\title{
Optical diagnostics of selective laser melting and monitoring of single-track formation
}

\author{
Andrey Gusarov ${ }^{1}$, Dmitriy Kotoban ${ }^{1, *}$, and Ivan Zhirnov ${ }^{1}$ \\ ${ }^{1}$ Moscow State University of Technology “STANKIN”, 127994, Vadkovskii per. 1, Moscow, Russia
}

\begin{abstract}
The article presents the optical diagnostics results of the selective laser melting process of single-track production. The track defects detection (such as balling effect, powder free zone formation, sparking) was shown, as well as the visualization of the independent particles consolidation in a solid track. The metal evaporation and the formation of the melt pool specific gas dynamic conditions were considered as important physical phenomena. The velocities of the particle emission from the melt pool, the rate of their involvement, and the velocity of the gas flow were estimated. The results make it possible to evaluate the kinetics of mass transfer under selective laser melting process. The surface thermal field of the laserirradiated zone strongly influences the material qualitative characteristics after selective laser melting. The results becomes the basis for the development of optical monitoring and diagnostic systems for laser additive manufacturing processes based on the melt pool temperature online controlling.
\end{abstract}

\section{Introduction}

The first strategy of scientific and technological development of Russia consisting in the transition to the new industries is directly related to additive manufacturing i.e. to the technologies of the metal, ceramics or polymers parts $3 \mathrm{D}$ printing. Modern additive technologies are the new paradigm for the new quality industrial product development and manufacturing $[1,2]$. The rearward face of the extensive development of additive manufacturing is its limitations, such as: build material limitations, low reproducibility and low productivity [3]. The most common and prospective additive manufacturing technologies (selective laser or electron beam melting, 3D laser cladding) do not provide either sufficient process online control or quality control of the material [4].

The basis for active control systems developing is the results of the optical diagnostics of selective laser melting (SLM) process $[5,6]$. The previous works showed actual results: the real (not brightness) temperature estimating method was found $[7,8]$, the process parameters influence on the track formation was evaluated [9], and the external conditions influence on the process was determined [10]. The laser-irradiated area visualization and numerical simulation provides considering all physical factors and phenomena during the laser processing [11, 12].

Optical diagnostics involves the use of a high-speed CCD camera allows visual monitoring of fast processes with high resolution, an infrared camera allows analyzing the thermal cycle of the treatment zone, and a pyrometer measures the average temperature of a small area of the treatment zone $[13,14]$. A serious problem in the way of wide additive production technologies industrialization is the need for an integrated approach to the additive technologies qualification for industrial manufacturing. The present work is devoted to the combination of accumulated knowledge and new scientific research in the field of control of track formation, process kinetics, and evaluation of the temperature of the melt pool.

\section{Materials and methods}

Optical diagnostics was carried out on an experimental laboratory-scale selective laser melting machine developed in the laboratory of innovative additive technologies of MSTU "STANKIN" according to the scheme on the Fig. 1. The energy source was the fiber laser LK-200V (IPG-Photonics, Russia) with a maximum power is $200 \mathrm{~W}$, the radiation wavelength is $1070 \mathrm{~nm}$. The focal beam diameter is $100 \mu \mathrm{m}$, and the spot transverse energy distribution is similar to the Gaussian.

As a measuring device, a high-speed (HS) camera of the visible range Photron SA5 (USA) was used with a frequency of $10 \mathrm{kHz}$ (frames / s) (exposure $\approx 0.1 \mathrm{~ms}$ ) and a spatial resolution of $0.1 \mathrm{px} / \mu \mathrm{m}$, as well as infrared (IR) FLIR Phoenix RDAC camera (Flir, USA) (working wavelength range is $1100-1700 \mathrm{~nm}$ ) with a frequency of $340 \mathrm{~Hz}$ (exposure time: $3 \mathrm{~ms}$ ) and a resolution of 0.87 pixels / micron. The survey frequency and resolution was limited by the capacity of the data bus. To exclude the laser radiation exposure of the HS-camera CCDmatrix, a notch-filter cuts off the wavelength of $1064 \pm$ $20 \mathrm{~nm}$ was used. Optical instruments were installed in

\footnotetext{
* Corresponding author: kotobandv@mail.ru
} 
the working chamber at an angle of at least $45^{\circ}$ to the surface of the substrate.

The austenitic stainless steel type AISI321 (12H18N9T, JSC Polema, Russia) with powder fraction of 0-40 $\mu \mathrm{m}$ and a molybdenum powder Mo 99,5\% (Amdry 313X, Oerlicon Metco) with powder fraction of 30-75 $\mu \mathrm{m}$ were used as the initial powders. As a substrate, the 321 steel plates of $4 \mathrm{~mm}$ were used in the work. Steel powder elemental composition is \% mass (Fe - balance, C - 0.1, Si - 0.68, Mn -0.9, Ti - 0.92, Cr 17.1, Ni - 9.7, S - 0.01, P - 0.03, H2O - 0.022).. The powders were produced by gas atomization and presented almost the spherical shape and homogeneous fraction distribution. The powder were sieved with 0.050 mesh (mesh cell is $50 \mu \mathrm{m})$ and dried in the vacuum oven at $120^{\circ} \mathrm{C}$ for 2 hours. The substrate was sandblasted and the surface was cleaned with alcohol.

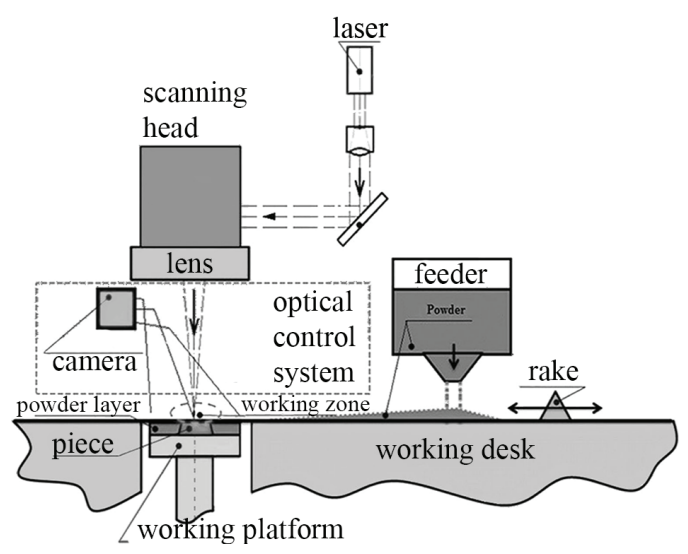

Fig. 1. Optical diagnostics equipment scheme coupled with SLM unit.

First SLM optical diagnostics experiments were carried out with 321 steel powder, which was uniformly leveled on the substrate with thickness of $100 \mu \mathrm{m}$ (the controlling was provided by automatic leveling system). The laser beam pass the lines of $15 \mathrm{~mm}$ in length on the powder surface using different process parameters: laser radiation power of $30 \mathrm{~W}$, beam scanning speed of 50$300 \mathrm{~mm} / \mathrm{s}$. The visible and thermography captures were saved and analyzed.

The second stage experiments were carried out with molybdenum powder with the following process parameters: powder leveling thickness was $100 \mu \mathrm{m}$, the laser power of 100 and $170 \mathrm{~W}$, the beam scanning speed of 50,75 and $100 \mathrm{~mm} / \mathrm{s}$.

The third step consists in the similar investigation with steel powder with the laser power of $100 \mathrm{~W}$, the beam scanning speed of 50, 75 and $100 \mathrm{~mm} / \mathrm{s}$. The step objective was to found the difference of steel and molybdenum process.

The final stage was carried out without powder leveling by 321 steel substrate scanning with scanning speed of 20 and $200 \mathrm{~mm} / \mathrm{s}$ and laser power of $170 \mathrm{~W}$.

For each stage of experiments, the IR and visible range data were collected, saved and analyzed. The picture analysis consists the particle tracking velocity method.

\section{Results and discussion}

The results of the first study showed the degradation of the track (by single spheres, the balling effect (see Fig. 2 ), and the presence of a changing zone without a powder surrounding the built track (see Fig. 3). Obviously, the formation of single spheres in the track results from the reduction of the specific energy on the track unit length. The IR-camera (Fig. 2) data shows at lower power, the maximum temperature remains virtually unchanged, but the temperature distribution changes significantly. Therefore pyrometry (where the signal value is averaged by the matrix) shows qualitative changes in the workspace, but a study is almost impossible with this type of optical mean. Meanwhile, the uniformity of the molten bath can be estimated by applying the methods of digital filtering and coordinate measurement, as well as by calculating of the longitudinal track interruptions number.

Formation of a powder-free zone almost always follows the SLM process. The video images showed powder particles movement directed to the center of the laser-irradiated zone during powder heating and consolidation into a monolithic track. The movement id directly influenced by the applied specific energy

For the steel powder, the consolidation proved to be so fast that it did not possible to deep investigation of the consolidation mechanism. Obviously, the consolidation time could characterize this process [15]. For standard metals and alloys, the melting and fusion time was less than $1 \mathrm{~ms}$ apparently due to their fluidity in liquid state.

For the second stage of the experiments, the single tracks were obtained after laser scanning of the molybdenum powder. The choice of molybdenum was proved by its extremely high melting point $(\mathrm{Tm}=2620$ $\left.{ }^{\circ} \mathrm{C}\right)$. Optical diagnostics of the process showed a clear picture of evaporation from the laser exposure zone (Fig. 4 ). Due to the high melting point of the used powder, the single powder particles located outside the melt pool are not fused among themselves and are in motion induced by the evaporation-driven gas flux. The single frame in Fig. 4a shows a powder-free zone appears during the motion of particles adjacent to the laser exposure zone (the melt pool). These particles do not have metallurgical contact with the substrate and are freely displaced by the gas dynamical forces. Serial images overlaying (Figure 4b) allows determining the particles motion path. As it is shown at the image, all moving particles on the substrate are directed to the center of the melt pool. Further, some non-molten particles or liquid particles released from the melt pool move up and out by the evaporation-driven gas flux. Evidently, the process intrinsic evaporation stream is directed perpendicular to the melt pool surface forms a zone of reduced pressure in the region adjacent to the melt pool, and the resulting gas stream involves the powder particles. Similarly, the third stage of work with steel powder was carried out. Using serial images when observing the motion of the same single particles, the velocities of their displacement and the value of the driving force could be calculated (Table 1, 2). 
a)

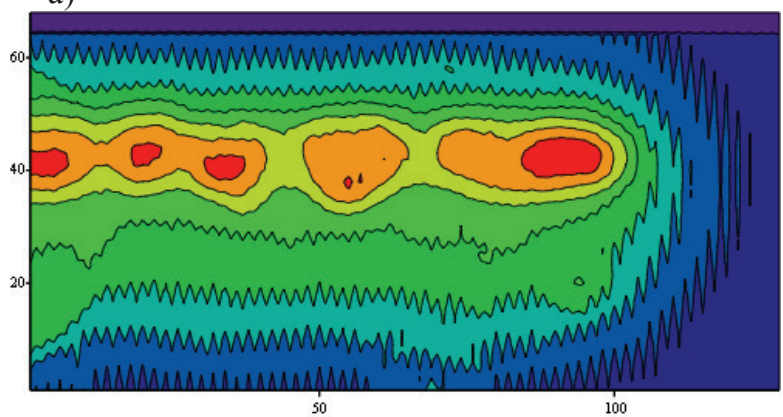

$\mathrm{A}^{\mathrm{T}}$ b)

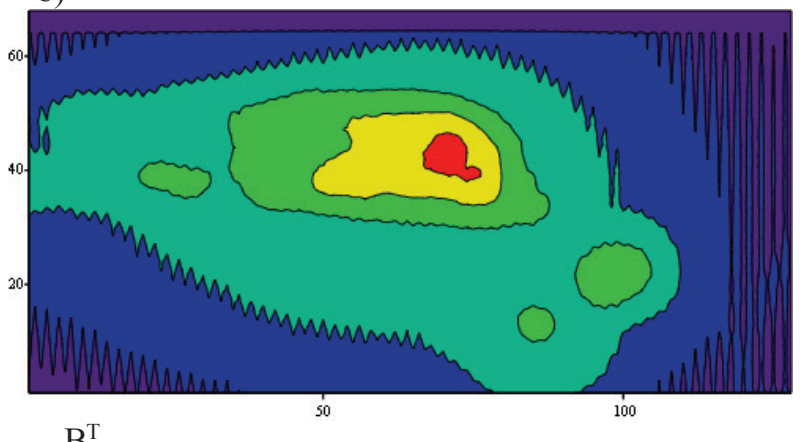

$\mathrm{B}^{\mathrm{T}}$

Fig. 2. Distribution of IR-camera signal for unstable track (a) and stable track (b). The process parameters: laser radiation power of 30 W, scanning speed of (a) $300 \mathrm{~mm} / \mathrm{s}$, (b) $100 \mathrm{~mm} / \mathrm{s}$.
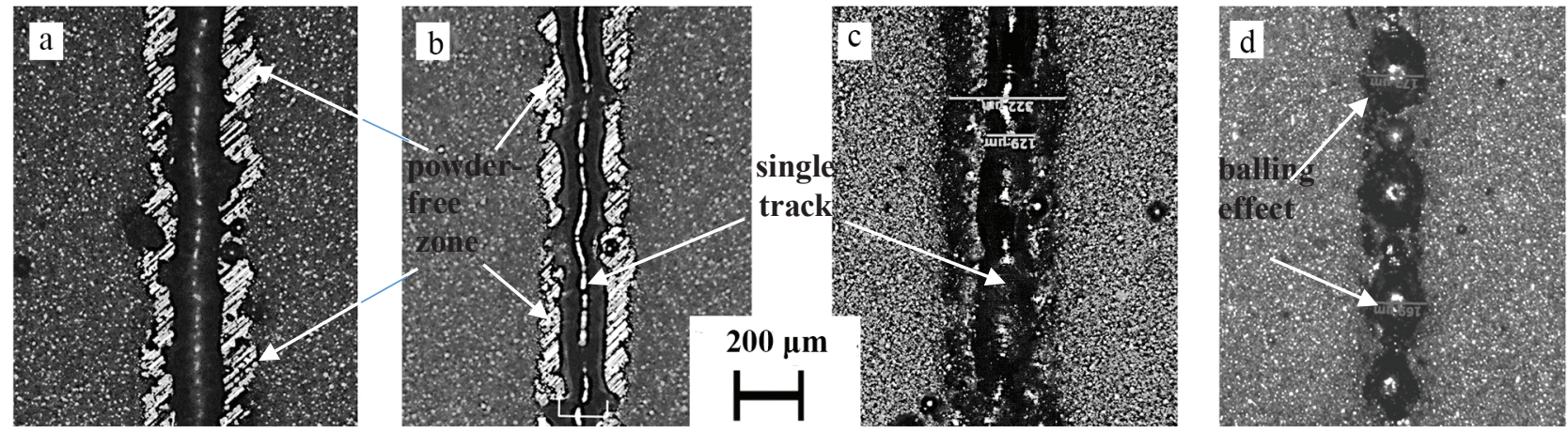

Fig. 3. Melted and solidified under different process parameters tracks from the steel powder (top view, the powder is not cleaned, optical microscopy is used): a) laser power is $30 \mathrm{~W}$, scanning speed is $100 \mathrm{~mm} / \mathrm{s}, \mathrm{b}) 30 \mathrm{~W}, 150 \mathrm{~mm} / \mathrm{s}, \mathrm{c}) 30 \mathrm{~W}, 200 \mathrm{~mm} / \mathrm{s}, \mathrm{d}) 30 \mathrm{~W}$, $300 \mathrm{~mm} / \mathrm{s}$.

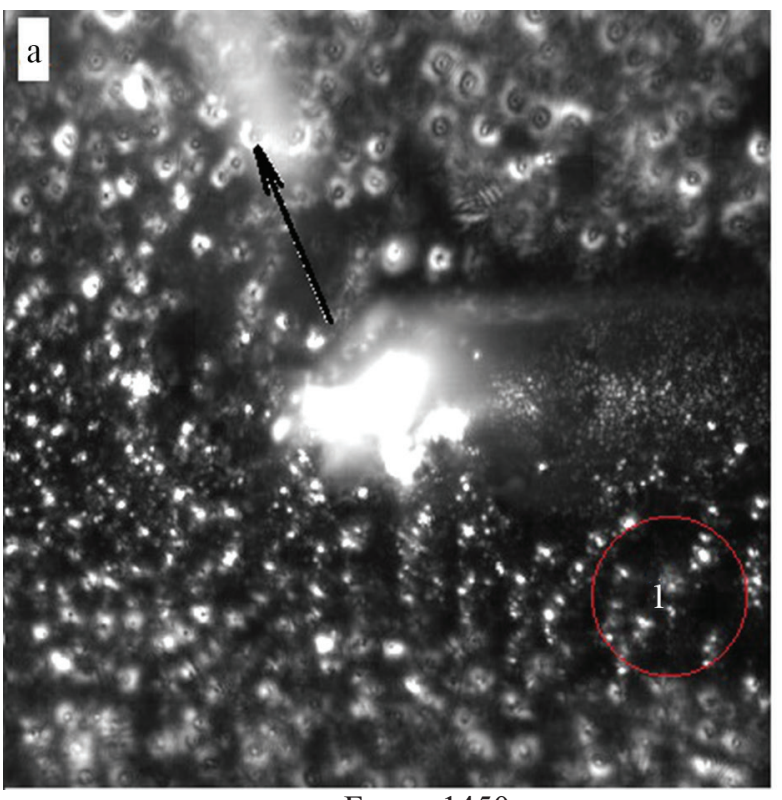

Frame $1450 \mathrm{~s}$

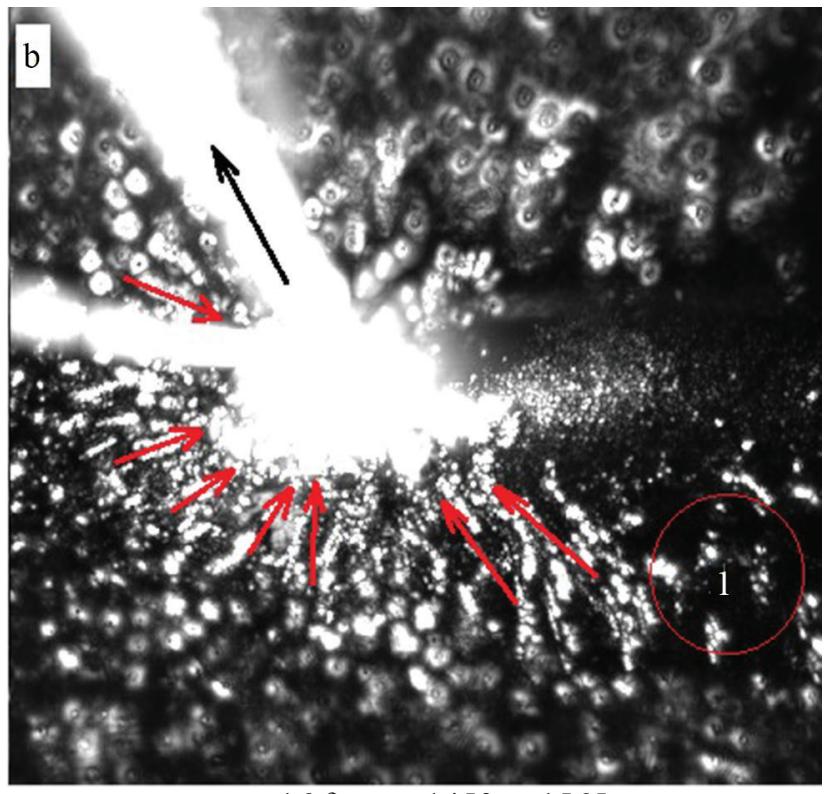

16 frames 1450 to $1565 \mathrm{~s}$

Fig. 4. The visualization obtained from the HS-camera in SLM process of molybdenum powder: a) single frame, b) overlapped series of 16 frames, 1- forming powder-free zone. 
Table 1 presents the calculated parameter values for both powders that move out from the laser exposure zone. The data was provided by image treatment using the specific automatized calculation software with PTV.

Table. 1. Parameters characterized the powder particles movement in gas dynamic flux in SLM process out from the laser exposure zone

\begin{tabular}{|c|c|c|}
\hline & 321 steel & Mo \\
\hline Sphere radii, $\mathrm{m}$ & $45 \cdot 10^{-6}$ & $53 \cdot 10^{-6}$ \\
\hline Volume, $\mathrm{m}^{3}$ & $3,82 \cdot 10^{-13}$ & $62,3 \cdot 10^{-14}$ \\
\hline Density, $\mathrm{kg} / \mathrm{m}^{3}$ & 7760 & 10220 \\
\hline Mass, kg & $2961 \cdot 10^{-6}$ & $6370 \cdot 10^{-6}$ \\
\hline Exposure time, $\mathrm{s}$ & $3 \cdot 10^{-4}$ & $4 \cdot 10^{-4}$ \\
\hline Path distance, $\mathrm{m}$ & $159 \cdot 10^{-6}$ & $636 \cdot 10^{-6}$ \\
\hline $\begin{array}{c}\text { Particle velocity } \\
\mathrm{m} / \mathrm{s}\end{array}$ & 0,53 & 1,59 \\
\hline Acceleration, $\mathrm{m} / \mathrm{s}^{2}$ & 1767 & 3975 \\
\hline Lifting force, $\mathrm{N}$ & $5,23 \cdot 10^{-6}$ & $25,3 \cdot 10^{-6}$ \\
\hline
\end{tabular}

Table 2. Parameters characterized the powder particles movement in gas dynamic flux in SLM process in the center of laser exposure zone

\begin{tabular}{|c|c|c|}
\hline & 321 steel & Mo \\
\hline Sphere radii, $\mathrm{m}$ & $27,8 \cdot 10^{-6}$ & $23 \cdot 10^{-6}$ \\
\hline Volume, $\mathrm{m}^{3}$ & $8,95 \cdot 10^{-14}$ & $5,09 \cdot 10^{-14}$ \\
\hline Density, $\mathrm{kg} / \mathrm{m}^{3}$ & 7760 & 10220 \\
\hline Mass, $\mathrm{kg}$ & $694 \cdot 10^{-6}$ & $521 \cdot 10^{-6}$ \\
\hline Exposure time, $\mathrm{s}$ & $2 \cdot 10^{-4}$ & $12 \cdot 10^{-4}$ \\
\hline $\begin{array}{c}\text { Path distance, } \mathrm{m} \\
\text { Particle velocity } \\
\mathrm{m} / \mathrm{s}\end{array}$ & $59 \cdot 10^{-6}$ & $146 \cdot 10^{-6}$ \\
\hline $\begin{array}{c}\text { Acceleration, } \mathrm{m} / \mathrm{s}^{2} \\
\text { Lifting force }, \mathrm{N}\end{array}$ & 1475 & 0,12 \\
\hline
\end{tabular}

(Particle tracking velocimetry) method. It could be noted that for more dense particles of molybdenum powder, the values of the lifting force are much higher than for steel powder particles.

Table. 2 contains data on the calculation of the velocity of the particles moving toward the center of the melt pool. For the less dense particles of the 321 steel powder, the entrainment velocity into the melt pool is higher than for the molybdenum powder particles. This does not agree with the data in Table. 1, where the velocity of molybdenum particles is higher than for steel particles. Apparently, molybdenum particles require more time to accelerate (because their inertia is higher due to mass), and thus could develop a greater speed. More detailed information could be obtained from numerical simulation. At present, it is obvious that the driving force for the movement of particles is the evaporation flux from the laser exposure zone perpendicular to the melt pool surface.

The experiments on the visualization and calculation of the velocity of the gas evaporation flux passed without using a powder on a 321 steel surface. The reason was to eliminate the particles ejected from the melt pool due to the flood exposure. The other one was to verify the evaporation flux velocity is higher than the particles one.
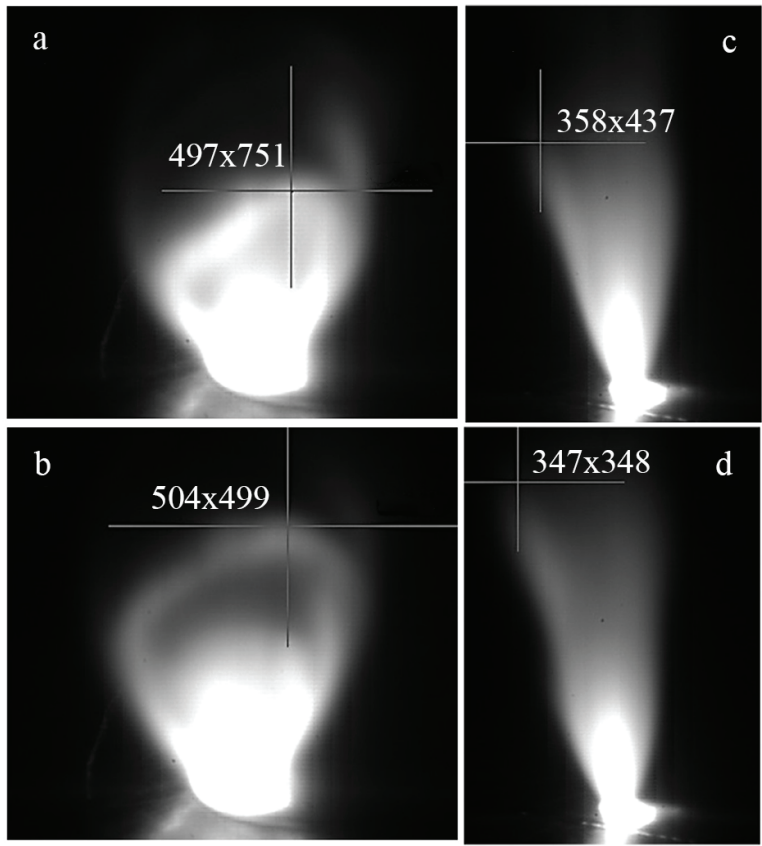

$347 \times 348 \quad d$

Fig. 5. Image series of the 321 steel plate melting Process parameters: laser power is $170 \mathrm{~W}, \mathrm{a}, \mathrm{b}$ ) scanning speed is 20 $\mathrm{mm} / \mathrm{s}, \mathrm{c}, \mathrm{d}$ ) scanning speed is $300 \mathrm{~mm} / \mathrm{s}$ 
Table. 3. Vapor velocity calculation for scanning speed of $20 \mathrm{~mm} / \mathrm{s}$

\begin{tabular}{|c|c|c|c|c|c|c|c|c|}
\hline & $\mathrm{x}$ & $\mathrm{y}$ & $\begin{array}{c}\text { Moving } \\
\text { distance, px. }\end{array}$ & $\begin{array}{c}\text { Moving } \\
\text { distance, } \mathrm{m}\end{array}$ & Exposure time, $\mathrm{s}$ & $\begin{array}{c}\text { Vapor } \\
\text { velocity, } \mathrm{m} / \mathrm{s}\end{array}$ & Average & Std. dev. \\
\hline \multirow{2}{*}{1} & 501 & 595 & \multirow{2}{*}{26} & \multirow{2}{*}{0,00026} & \multirow{2}{*}{0,0001} & \multirow[t]{2}{*}{3} & \multirow{10}{*}{3} & \multirow{10}{*}{1,14} \\
\hline & 509 & 570 & & & & & & \\
\hline \multirow{2}{*}{2} & 405 & 649 & \multirow{2}{*}{20} & \multirow[t]{2}{*}{0,00020} & \multirow{2}{*}{0,0001} & \multirow[t]{2}{*}{2} & & \\
\hline & 400 & 630 & & & & & & \\
\hline \multirow{2}{*}{3} & 497 & 571 & \multirow{2}{*}{28} & \multirow[t]{2}{*}{0,00028} & \multirow{2}{*}{0,0001} & \multirow[t]{2}{*}{3} & & \\
\hline & 505 & 544 & & & & & & \\
\hline \multirow{2}{*}{4} & 497 & 571 & \multirow{2}{*}{72} & \multirow[t]{2}{*}{0,00072} & \multirow{2}{*}{0,0002} & \multirow[t]{2}{*}{4} & & \\
\hline & 504 & 499 & & & & & & \\
\hline \multirow{2}{*}{5} & 158 & 483 & \multirow{2}{*}{49} & \multirow[t]{2}{*}{0,00049} & \multirow{2}{*}{0,0001} & \multirow[t]{2}{*}{5} & & \\
\hline & 153 & 434 & & & & & & \\
\hline
\end{tabular}

Table. 4. Vapor velocity calculation for scanning speed of $300 \mathrm{~mm} / \mathrm{s}$

\begin{tabular}{|c|c|c|c|c|c|c|c|c|}
\hline & $\mathrm{x}$ & $\mathrm{y}$ & $\begin{array}{r}\text { Moving } \\
\text { distance, px. }\end{array}$ & $\begin{array}{r}\text { Moving } \\
\text { distance, } m\end{array}$ & $\begin{array}{l}\text { Exposure } \\
\text { time, s }\end{array}$ & $\begin{array}{c}\text { Vapor } \\
\text { velocity, } \mathrm{m} / \mathrm{s}\end{array}$ & Average & Std. dev. \\
\hline \multirow{2}{*}{1} & 654 & 428 & \multirow{2}{*}{79} & \multirow{2}{*}{0,00079} & \multirow{2}{*}{0,0001} & \multirow{2}{*}{8} & \multirow{8}{*}{9} & \multirow{8}{*}{0,93} \\
\hline & 648 & 349 & & & & & & \\
\hline \multirow{2}{*}{2} & 679 & 402 & \multirow{2}{*}{81} & \multirow{2}{*}{0,00081} & \multirow{2}{*}{0,0001} & \multirow{2}{*}{8} & & \\
\hline & 692 & 322 & & & & & & \\
\hline \multirow{2}{*}{3} & 602 & 433 & \multirow{2}{*}{99} & \multirow{2}{*}{0,00100} & \multirow{2}{*}{0,0001} & \multirow{2}{*}{10} & & \\
\hline & 612 & 334 & & & & & & \\
\hline \multirow{2}{*}{4} & 358 & 437 & \multirow{2}{*}{90} & \multirow{2}{*}{0,00090} & \multirow{2}{*}{0,0001} & \multirow{2}{*}{9} & & \\
\hline & 347 & 348 & & & & & & \\
\hline
\end{tabular}

It proves that the motion of the powder particles in SLM process is driven by the evaporation gas flux as well (the other reason apparently is melt pool dynamics). At this stage of the experiments, the melting of the substrate was carried out without a powder (Fig. 5). When calculating the speed of vapor, the image scale of $10 \mu \mathrm{m} / \mathrm{px}$ was used. Table. 3 and 4 presents the calculated velocity of the gas flux during scanning of the 321 steel substrate at a speed of $20 \mathrm{~mm} / \mathrm{s}$ and $300 \mathrm{~mm} / \mathrm{s}$. The average value of the vapor velocity for several points in the image is $3 \mathrm{~m} / \mathrm{s}$. The value is much higher than the beam scanning speed and single particle velocities. The standard deviations contain high values relative to the mean value, which apparently could depend on the particles sampling being studied in each case. Due to the fact that the flux velocity at different points will be various, mean values with deviations are representative qualitatively.

It should be noted that as the scanning speed increases, the velocity of the evaporation gas flux from the melt pool increases significantly. Apparently, this is due to the decrease in the cross section of the flow passage, while the flow rate hold constant.

The mechanism of the powder-free zone formation, therefore, consists in the formation of a gas-dynamic flux in the laser exposure zone induced by the draft (stack effect) by evaporation flux from the melt pool surface. At the same time, the powder particles are involved along with the gas flux, incorporated into the melt pool or being thrown out in the form of sparks. Evaporation flux, apparently, directly depends on the temperature field on the surface of the melt pool, i.e. it is related to the process parameters. Simple conclusions show that the evaporation, coupled with the hydrodynamic behavior of the melt pool under the influence of laser radiation, form limitations in the technology of laser layer-by-layer 3D synthesis of the parts, as well as in other laser technologies. A similar result was obtained in [16], where the authors found similar effects (similar to Bernoulli effect) and described the medium gas dynamics behavior in the SLM process. The parameters having a significant influence on physical processes in the melting zone must be controlled. As shown, apparently the temperature, its distribution or the initial signal (or brightness temperature) of the IR-camera or pyrometer can be used for contactless process control, based on the developed criteria. The problem of estimating the actual values of the melt pool surface temperatures become particularly difficult due to the specifics of the techniques and the direct dependence of the signal on the radiation and signal propagation conditions from the treatment zone. In addition, the question of the calibration of optical elements in the complete set of the optical path of the SLM machine is currently being solved.

\section{Conclusion}

The use of diagnostic tools as the HS-camera and the IRcamera allows studying the fast processes occurring in the laser exposure zone, diagnosing the reasons of the particles motion leading to the formation of non-uniform distribution of the melted material volume. Some of these processes are unfavorable and can affect the 
quality of the part, made from the superposition of single tracks stacked next to each other.

The results of the study showed the kinetics of particles consolidation into a monolithic track and a gasdynamic mechanism of the powder-free zone formation. In the course of the study, the velocities of the particles involved in the melt pool and particles ejected from the treatment zone were calculated. The value of the velocity of the evaporation gas flux, which is the cause of the motion of particles in the SLM process, is established. The methods and limitations of gas flow control are shown.

This work has been financed by the sources of Russian Science Foundation (grant agreement №15-19-00254 from 18.05.2015).

\section{References}

1. S. N. Grigoriev, T.V. Tarasova, Met. Sci. Heat Treat. 57(9-10), 579-584 (2016)

2. F.Domniţa, H. Rotaru, MATEC Web of Conferences 94 (2017)

3. M. Baumers, P. Dickens, C. Tuck, R. Hague, Technol. Forecast. Soc. 102, (2016)

4. J.-P. Kruth, L. Froyen, J. Van Vaerenbergh, P. Mercelis, M. Rombouts, B.Lauwers, J Mat Proc Tech 149, 1, (2004)

5. I. Smurov, IV International WLT-Conference on Lasers in Manufacturing, 537-546 (2007)

6. M. Doubenskaia, M. Pavlov, Y. Chivel, Key Engineering Materials 437, 458-461 (2010)
7. M. A. Doubenskaia, I. V. Zhirnov, V. I. Teleshevskiy, P. Bertrand, I. Y. Smurov, Mater. Sci. Forum 834, 93-102 (2015)

8. P. Y. Peretyagin, I. V. Zhirnov, Y. G. Vladimirov, T. V. Tarasova, A. A. Okunkova, Russian Engineering Research 35, 6, 473-476 (2015)

9. I. Zhirnov, C. Protasov, D. Kotoban, A.V. Gusarov, T. Tarasova, J. Therm. Spray Technol. 26, 648, 113. (2017)

10. M. Doubenskaia, D. Kotoban, I. Zhirnov, Mech. Ind. 17, 7, 707 (2016)

11. I. Zhirnov, I. Yadroitsava, I. Yadroitsev Mater. Sci. Forum. 828, 474-481 (2015)

12. I. O. Kovaleva, S. N. Grigoriev, A. V. Gusarov, Phys. Proc. 56, 421-428 (2014)

13. P. Lott, H. Schleifenbaum, W. Meiners, K. Wissenbach, C. Hinke, J.Bültmann, Phys. Proc. 12, 683-690 (2011)

14. J.-P. Kruth, P. Mercelis, J. Van Vaerenbergh, T. Craeghs, Proc. 3rd int. conf. adv. res. virt. and rapid prototyping, 521-527 (2007)

15. C. E. Protasov, R. S. Khmyrov, S. N. Grigoriev, A. V. Gusarov Int. J. Heat Mass Transfer 104, 665-674 (2017)

16. M. J. Matthews, G. Guss, S. A. Khairallah, A. M. Rubenchik, P. J. Depond, W. E. King, Acta Mater. 114, 33-42 (2016) 